\title{
Evaluation of Energy Use in Public Housing in Lagos, Nigeria: Prospects for Renewable Energy Sources
}

\author{
Isidore C. Ezemaa ${ }^{,}$, Abiodun O. Olotuahb ${ }^{\mathrm{b}}$ and Olabosipo I. Fagbenlec \\ ${ }^{a}$ Department of Architecture, Covenant University, Ota, Nigeria \\ ${ }^{b}$ Department of Architecture, Federal University of Technology, Akure, Nigeria \\ c Department of Building Technology, Covenant University, Ota, Nigeria
}

\begin{abstract}
Even though domestic energy can be from either renewable or non-renewable sources, the former is preferred because of its role in reducing both the operational energy intensity and carbon footprint. Given the positive role renewable energy plays in the energy mix, this paper examined the pattern of operational energy use with particular reference to the renewable and non-renewable energy content in medium and high density public residential buildings in Lagos, Nigeria. A survey research method was adopted for primary data collection while data analysis was by descriptive statistics. The study found that renewable energy use in the residential units is very low. In contrast, there was high dependence of the occupants on non-renewable direct fuel combustion through the use of fossil fuel-driven privately-owned electricity generators for electricity supply as a result of the inadequate supply from the national grid. In addition to the relatively high operational energy intensity observed in the studied buildings, the findings have implications for the safety, health and wellbeing of the building occupants as well as for carbon emissions from the buildings and for overall environmental sustainability. Recommendations to increase renewable energy use in new buildings and as retrofits in existing buildings were made.
\end{abstract}

Keywords: Lagos, Nigeria, non-renewable energy, operational energy, public housing, renewable energy

Article History: Received Oct 18, 2015; Received in revised form January 14, 2016; Accepted January 30, 2016; Available online

How to Cite This Article: Ezema, I.C., Olotuah, A.O., and Fagbenle, O.I, S. (2016) Evaluation of Energy Use in Public Housing in Lagos, Nigeria: Prospects for Renewable Energy Sources. Int. Journal of Renewable Energy Development, 5(1),15-24. http://dx.doi.org/10.14710/iired.5.1.15-24

\section{Introduction}

Buildings play a vital role in global energy consumption and carbon dioxide emissions. Carbon dioxide emissions from buildings are due largely to the high carbon content of delivered energy for building operations (Vossenaar \& Jha, 2010). Building-related greenhouse gases (GHGs) emissions of which carbon dioxide is an important part, has been on the increase with rapid urbanization especially in developing countries where increased urban population with access to improved income has resulted in increased energy consumption (IPCC, 2007). Housing constitutes an integral part of the building stock of any society and documented energy consumption patterns for housing confirm their importance (UNEP, 2007).

Energy use and carbon intensity are indices of the environmental sustainability of a building as they contribute to global warming and ultimately, climate change. Household energy use and carbon intensity are related through the energy mix which describes the relative contribution of various energy sources to the total energy profile. In general, the higher the renewable energy content in the energy mix, the lower the energy intensity in primary energy terms. In order to reduce energy use intensity and carbon emissions from the housing sector, a combination of low-carbon energy and energy efficiency measures are recommended (IPCC, 2007). One such low-carbon energy source is renewable energy which includes solar energy, wind energy, geothermal energy, ocean energy, bio-energy and hydropower. Renewable energy is a sustainable form of energy as it is from naturallyoccurring, non-depleting resources. Apart from being low in primary energy impact, it is a low-carbon form of energy that helps to keep the carbon footprint of buildings low.

*Corresponding author:

Email: isidore.ezema@covenantuniversity.edu.ng 
Citation: Ezema, I.C., Olotuah, A.O., and Fagbenle, O.I, S. (2016) Evaluation of Energy Use in Public Housing in Lagos, Nigeria: Prospects for Renewable Energy Sources. Int. Journal of Renewable Energy Development, 5(1),15-24, http://dx.doi.org/10.14710/ijred.5.1.15-24

$\mathrm{P}$ a g e | 16

In spite of the obvious advantages of renewable energy, its uptake in various contexts especially in developing countries has not been seamless as it is beset by a myriad of barriers. In general, the barriers to renewable energy technology (RET) deployment include financial barriers (Moula et al., 2013; Nasirov, Silva \& Agostini, 2015), technological or grid connection barriers (Nasirov et al., 2015), regulatory or administrative barriers (Moula, 2013), as well as social acceptability barriers (Sriwannawit \& Laestadius, 2013; Moula et al., 2013).

In Nigeria, available data from the International Energy Agency (EIA) as presented by Intec (2015), show that total energy consumption in 2012 was estimated at $116.5 \mathrm{Mtoe}$ with bio-fuels sources constituting about $85 \%$ and residential consumption ascribed mostly to household cooking taking up about $90 \%$ of the bio-fuels. Inefficient combustion of fuelwood and other forestry products dominated the domestic energy profile. Similarly, total energy consumption distributed according to economic sectors indicate that residential consumption at 78\% eclipsed industrial and other uses which make up the remaining $22 \%$. With respect to electricity consumption, the residential sector is estimated to consume between 50.4\% (Akinbami \& Lawal, 2010) and 65\% (UNDP, 2010) which are clearly above the world average of about 31\% (Saidur, Masjuki \& Jamaliddin, 2007). Hence, in terms of energy consumption, the residential sector in Nigeria is very important. Paradoxically, the actual per capita electrical energy consumption is among the lowest in the world (USEIA, 2015). From the foregoing, the energy situation is not only inadequate but also inefficient thus underscoring the need for RETs in the study context.

Even though national renewable energy targets (IRENA, 2011) are far from being met, the use of renewable energy technology is gradually being established mostly in micro-level off-grid installations such as street lighting, water pumping, agriculture, refrigeration in rural medical centres, private residential buildings as well as in institutional buildings (Sambo, 2010). As indicated in a study by Eronini (2014), the use of photovoltaic systems is gaining ground in urban commercial and residential buildings mostly as a result of poor electricity supply from the national grid. Constraints to widespread use of RET in buildings have been identified and they include high initial cost of installation, dearth of technical knowhow and ineffective or unfavourable government policy (Ogunleye \& Awogbemi, 2011; Okedu, Uhunmwangho \& Promise, 2015). As a result, earlier uptake of RETs was associated with relatively high income residences. With improved diffusion of the RET technology, there is the need to understand its use in low and medium income residences.

Against the above background, this study sought to evaluate the extent of use of both renewable energy technologies and non-renewable energy sources in high and medium density public housing estates in Lagos, Nigeria. While the non-renewable sources are dominated by fossil fuels, four main renewable energy options have been identified for micro- and off-grid purposes in Nigeria and they are: small hydro, solar, biomass and wind (Intec, 2015). In the study context of Lagos, however, solar and wind installations have more potential for unhindered widespread use. This is because the resource base for small hydro and biomass installations, that is, flowing steams and municipal solid waste handling points respectively, are location-specific and hence not accessible to the housing units under study. The renewable energy sources of focus are therefore solar and wind energy. In addition, the study area is endowed with good solar intensity and prevailing wind speed conditions (ECN, 2005). In order to situate the study properly, the pattern of operational energy use in the buildings was considered and the renewable and non-renewable aspects identified.

\section{The Energy Scenario in Nigeria}

There are various sources of energy in Nigeria which include non-renewable sources such as fossil fuels and renewable energy sources (ECN, 2003). Nigeria has abundant renewable energy sources which have been identified by source assessment studies to include solar energy, wind energy, biomass and hydropower (Shaaban \& Petinrin, 2014). However, delivered energy in form of electricity to households falls short of expectation. As at 2008, per capita electricity consumption in Nigeria was estimated at $125 \mathrm{kWh}$ as against $4500 \mathrm{kWh}, 1934 \mathrm{kWh}$ and $1379 \mathrm{kWh}$ in South Africa, Brazil and China respectively (FGN, 2009). The scenario has not changed remarkably as estimates by (World Bank, 2013) indicated that per capita electricity consumption was $149 \mathrm{kWh}$ and $156 \mathrm{kWh}$ in 2011 and 2012 respectively.

In addition, the electrical energy mix in Nigeria is dominated by two main sources namely non-renewable thermal and renewable hydropower (Ajayi, 2013). Incidentally, the mix is lopsided with about $82 \%$ of electricity coming from thermal power generation using non-renewable resources and $18 \%$ from renewable hydropower generation (KPMG, 2013). In addition, the performance indicators of the thermal power plants have been found to be below expectation. Using performance indices that included plant capacity, plant use factor, load factor and utilisation factor, some studies (Obodeh \& Esabunor, 2011; Oyedepo et al, 2014) revealed that the Nigerian thermal power plants had performed sub-optimally. As a result, thermal efficiency level is low as earlier indicated for non- OECD (Organisation for Economic Cooperation and Development) countries by (Taylor et al, 2008). In this direction and as recommended by Afa and Anerih (2013), Nigeria needs to broaden her electrical energy 
mix in such a way that no energy source contributes more than $40 \%$ to the total electrical energy supply.

In addition, electricity supply is erratic and access is available only to about $55.6 \%$ of the population (World Bank, 2014). The foregoing is corroborated by an earlier study by Otegbulu (2011) which found that a majority of households in Lagos get grid electricity for between 1 hour and 5 hours daily as a result of which more than $60 \%$ of the households use private generators for captive electricity generation. Hence, Nigeria can be described as characterized by the suppressed demand situation with respect to grid electricity as enunciated by Spors (2011). Suppressed demand is a situation where energy services are either insufficient or inaccessible to those who need it. This situation could arise due to insufficient capacity or unaffordable electricity tariff. Low capacity adequately describes the Nigerian electricity supply situation and in building up capacity, all available energy sources need to be exploited. Given the inadequate electricity supply situation and the poor diffusion of grid electricity especially in the rural areas of Nigeria, the use of renewable energy has been strongly recommended (Akpan \& Isihak, 2013; Elusakin, Ajide \& Diji, 2014)

Solar energy is particularly suitable for Nigeria because of all year round sunshine. With solar radiation estimated at $3.5-7.0 \mathrm{kWh} / \mathrm{m} 2 /$ day, the entire national energy demand can be met by solar energy (ECN, 2005). Wind energy potentials are moderately high especially in coastal areas like Lagos and in the northern part of the country where wind speeds at 10 metres height can be up to $5 \mathrm{~m} / \mathrm{s}$ (ECN, 2005). A number of researchers have advocated the adoption of off-grid electricity supply using renewable energy to address the poor diffusion of grid electricity especially in the remote and rural areas (Akpan \& Isihak, 2013; Elusakin et al, 2014). Given the vastness of the Nigerian rural communities and the cost of extending grid electricity to them, the use of renewable energy sources such as solar energy integrated within a smart grid network has been advocated (Emodi \& Yusuf, 2014). Even in urban locations such as Lagos where grid electricity is available, the use of renewable energy is highly advised given the erratic nature of the supply and increasing cost of grid electricity in financial and environmental terms.

In order to harness the abundant energy resources in Nigeria, the Energy Commission of Nigeria was established and there is in place a national Renewable Energy Master-plan (ECN, 2005). The government of Lagos State, Nigeria has also adopted a renewable energy policy aimed at encouraging the use of RET in order to limit GHGs emission and bridge the energy supply deficit in the area (LASG, 2012a). The specific renewable energy resources identified for Lagos include solar energy, wind energy and biomass as well as municipal solid wastes. Hence, there is a renewable energy master plan with expected targets for the various renewable energy components but adequate incentives for uptake especially at the residential building scale are not yet fully articulated. However, considering the huge solar and wind energy potentials in Nigeria, the targets of 500MW and 40MW for solar energy and wind energy respectively by the year 2025 as stipulated by ECN (2005) appears very conservative. The new National Renewable Energy and Energy Efficiency Policy (NREEEP) afford a fresh opportunity to set new targets and establish appropriate incentives for renewable energy use generally and in buildings (Federal Ministry of Power, 2015).

\section{Renewable Energy Use in Buildings}

According to the socio-economic survey of Nigeria conducted in 2009 (NBS, 2010), solar energy use by households was almost non-existent. In the study area Lagos, only $0.1 \%$ of households indicated that they use solar energy for lighting. In contrast, $86 \%$ use electricity as main domestic energy for lighting while about $12 \%$ use gas and kerosene. Similarly, for cooking energy, during the three years 2007-2009, kerosene remained the main cooking fuel in the study area (see Table 1). On the average, about $90 \%$ of all households use kerosene as main cooking fuel while less than $5 \%$ on the average use fuel wood. The low use of fuel wood is explained by the cosmopolitan nature of Lagos which encourages less use of lower order fuels such as fuel wood. From the foregoing, it is evident that energy use at the domestic level is dominated by grid electricity mainly from nonrenewable sources for lighting and appliances as well as kerosene for cooking.

Table 1:

Cooking Energy Use in Lagos Households

\begin{tabular}{llllll}
\hline & $\begin{array}{l}\text { Percentage } \\
\text { Electricity }\end{array}$ & Gas & Kerosene & $\begin{array}{l}\text { Fuel } \\
\text { wood }\end{array}$ & Coal \\
\hline 2007 & 2.8 & 3,8 & 89.7 & 3.1 & 0.6 \\
2008 & - & 6.2 & 91.1 & 2.7 & - \\
2009 & 1.1 & 2.2 & 87.6 & 8.7 & 0.4 \\
Average & 2.0 & 4.1 & 89.5 & 4.8 & 0.5 \\
\hline
\end{tabular}

Source: NBS, 2010.

Comparatively, a Brazilian study revealed that electricity accounted for $40 \%$ of household energy use while gas and firewood/charcoal accounted for $28 \%$ and $29 \%$ respectively (Gorini, 2014). Interestingly, the renewable content of grid electricity in Brazil traceable mainly to hydroelectricity is up to $45 \%$ (Luomi, 2014; Newborne \& Welham, 2014). Similarly, in the period from 2005 to 2012, the diffusion rate of solar water heater installations increased from $1.3 \%$ to about $4 \%$ (Gorini, 2014). In addition, wind energy generation and solar electricity generation reached 6500MW and 30MW respectively in 2013 (Barth et al, 2015). As a result, the operational energy intensity in Brazilian households is lower than in other upper middle income 
Citation: Ezema, I.C., Olotuah, A.O., and Fagbenle, O.I, S. (2016) Evaluation of Energy Use in Public Housing in Lagos, Nigeria: Prospects for Renewable Energy Sources. Int. Journal of Renewable Energy Development, 5(1),15-24, http://dx.doi.org/10.14710/ijred.5.1.15-24

$\mathrm{P}$ a g e $\mid 18$

countries (Newborne \& Welham, 2014). In a specific study of a residential building typology in Brazil, life cycle operational energy intensity was found to be $17,500 \mathrm{MJ} / \mathrm{m}^{2}$ (Paulsen \& Sposto, 2013). In contrast, the operational energy intensities in comparable Indonesian and Indian examples were found to be higher and in the range of $11600 \mathrm{MJ} / \mathrm{m}^{2}-32100 \mathrm{MJ} / \mathrm{m}^{2}$ and $37300 \mathrm{MJ} / \mathrm{m}^{2} \quad-66850 \mathrm{MJ} / \mathrm{m}^{2}$ respectively (Surahman \& Kubota, 2012a, 2012b; Ramesh, Prakash \& Shukla, 2013).

A study in India showed that aggregated electricity generation from renewable sources as at May 2013 was 28446.05MW (Sood et al, 2014). In addition, 6.655 million biogas plants and about 6.98 million square metres of solar water heating collector area has been installed (Sood et al, 2014). Wind energy is the fastest growing renewable energy sector in India with a generation capacity of $21268.3 \mathrm{MW}$ in 2014 which ranks India the fifth largest generator in the world (Sangroya \& Nayak, 2015).

In China, solar water heater is the most widely used RET (Yuan, Wang \& Zuo, 2013). Installed solar water heater collector area increased from 15 million square metres to 145 million square metres between 1998 and 2009 thus making China a dominant player in this aspect of renewable energy use (Yuan et al, 2013). In the aspect of photovoltaic installations in buildings, China lags behind Japan, USA and Germany but installed capacity indicated progressive increase from $135 \mathrm{MW}$ in 2005 to $156 \mathrm{MW}$ in 2009 (Yuan et al, 2013). China is also the world leader in wind energy utilization generating a total of 91424MW in 2013 (GWEC, 2014).

This paper focused on solar energy use through photovoltaic panels and wind energy use through wind turbines. However, given the relatively small land area in Lagos and the resultant dense urban fabric, emphasis was placed on off-grid building-mounted photovoltaic (PV) installations and small wind turbines mounted within residential areas. Even though hydroelectricity is regarded as renewable energy, it was not considered in this study because it is part of the national grid installations. Also, renewable energy from municipal solid waste was not considered as it is still at pilot stage in the study area.

\section{Materials and Methods}

The study is directed at operational energy use in residential buildings and the study context is Lagos, a prominent city in Nigeria. Lagos accounts for about 70 per cent of industrial investments, 90 per cent of foreign trade flows, 50 per cent of port revenue, 60 per cent of energy consumption and over 30 per cent of Nigeria's gross domestic product (GDP) (LASG, 2012b). Geographically, Lagos lies between latitudes $6^{\circ} 24^{\prime}$ and $6^{\circ} 41^{\prime}$ north of the equator and between longitudes $2^{\circ}$ $42^{\prime}$ and $3^{\circ} 42^{\prime}$ east of the Greenwich meridian (Ilesanmi, 2010). Bounded on the north, east and west by Ogun
State and on the south by the Atlantic Ocean, Lagos covers a gross area of about $3,577 \mathrm{~km} 2$, a sizeable proportion of which is made up of wetlands, thus making it the smallest in terms of land area of all the states in the Federal Republic of Nigerian (Jeje, 2013). The official 2006 population census in Nigerian put the population of Lagos at just over 8 million people and UN Habitat has projected a population of over 15 million by 2025 (UN Habitat, 2008). However, more recent projections for the population of Lagos put it at over 23 million by the end of 2015 (Lagos Bureau of Statistics, 2013).

The real estate sector in Lagos is very vibrant given the city's economic status, population and rate of urbanisation. In response to the housing need, there is a strong social housing content represented by Federal and State government housing provision agencies. At the State level, the Lagos State Development and Property Corporation (LSDPC) established under Edict No.1 1972 to provide affordable housing to low and medium income earners stands out. However, the real estate sector is dominated by the private sector most of whom are small players. Public housing managed on behalf of the state government by the LSDPC was selected for the study as it represented the most dominant in the study area.

Survey research method was used to elicit data on primary energy use in the buildings. The research population was the public housing units established by Lagos State Government between 1981 and 2005 for low and medium income earners located in mediumrise multi-family residential blocks in residential estates managed by the Lagos State Development and Property Corporation (LSDPC). Altogether, there are 31 such estates from where a sample of nine estates was taken randomly. The nine estates comprised 10,182 housing units which constituted the study population. Each housing unit is about $120 \mathrm{~m}^{2}$ in area. Taking each estate as a stratum of the population, a sample size of 1,075 housing units was drawn systematically and used for questionnaire administration for the study. The study was carried out between February and May, 2014. Altogether, 775 validly completed questionnaires were retrieved and used for analysis. The questionnaire elicited data on aggregate household operational energy consumption with respect to grid electricity (measured in $\mathrm{kWh}$ ) and direct fuel consumption (measured in litres and kilograms). Wood fuel consumption was not included in the study as the buildings were not designed to accommodate such. Also, data on renewable energy use and other energy management options were elicited. The data were analysed using descriptive statistics with the measures of central tendencies adopted as the appropriate statistical measure.

The results obtained from the survey were used in conjunction with relevant energy conventions and protocols to estimate energy consumption in primary 
energy terms at the operational level in the selected residential building typology. Such conventions include:

(i) Conversion of $\mathrm{kWh}$ to $\mathrm{MJ}$ which is the unit of primary energy (Hofstrand, 2008);

(ii) Conversion of direct fuel consumption to primary energy (GREET, 2010);

(iii) The use primary energy factor for grid electricity (IINAS, 2015).

The relevant equations are as presented below:

$\mathrm{OE}=\mathrm{PEoGE}+\mathrm{PEoDFC}$

Where OE is operational energy measured in megajoules (MJ), PEoGE is primary energy content of grid electricity measured in mega joules (MJ), PEoDFC is primary energy of direct fuel consumption measured in mega-joules (MJ).

PEoGE $=$ GE $\times 3.6 \times \mathrm{PEF}$

Where GE is grid electricity consumption measured in kilowatt hour (kWh), PEF is primary energy factor for grid electricity, 3.6 is conversion factor from $\mathrm{kWh}$ to mega-joule.

A simplified PEF for grid electricity in the study area was earlier estimated to be 2.83 (Ezema, 2015). In order to estimate electricity consumption in $\mathrm{kWh}$, the residents were asked in the questionnaire to state the amount paid for electricity on a monthly basis. The prevailing tariff regime was subsequently applied to the amount after allowing for the fixed charge.

PEoDFC = DFC $\times$ LHV

Where DFC is fuel consumption in litres, LHV is lower heating value of fuel.

With reference to $\mathrm{LHV}$, the default values as estimated by the IPCC and World Resources Institute WRI were used (IPCC, 2007; WRI, 2012).

\section{Results}

\subsection{Operational Energy Sources}

The energy end uses identified were lighting, cooling, domestic hot water, cooking, household appliances and water pumping. Also, operational energy sources for the buildings were found to be grid electricity and direct fuel combustion. The direct fuel used included kerosene also referred to as dual purpose kerosene (DPK), liquefied petroleum gas (LPG) and petrol or premium motor spirit (PMS). Grid electricity was the most preferred energy for operation of the buildings. Also, kerosene and liquefied petroleum gas (LPG) were the predominant cooking fuel. Given the low supply of electricity from the national grid, the residents resorted to the use of electricity generators which were powered by petrol or premium motor spirit (PMS). The use of diesel was also identified but the quantity was not significant and the diffusion was low.

As shown in Table 2, the average monthly expenditure on grid electricity using the median as measure of central tendency was estimated to be about $\$ 2,500.00$. Using the tariff regime in operation as at June, 2014 as obtained from the Ikeja Electricity Distribution Company (IKEDC), an electricity distribution company with jurisdiction over the study area, and taking note of the fixed service charge, the average consumption was estimated to be $100 \mathrm{kWh}$ monthly and $1200 \mathrm{kWh}$ annually per household. By applying equation 2 and a primary energy conversion factor for grid electricity of 2.83, the annual primary energy content of grid electricity was estimated to be $12226 \mathrm{MJ}$.

Table 2

Monthly Grid Electricity Consumption

\begin{tabular}{lll}
\hline Category & Frequency & $\mathbf{\%}$ \\
\hline 1000 naira and below & 28 & 3.6 \\
1001- 2000 naira & 124 & 16.0 \\
2001- 3000 naira & 247 & 31.9 \\
3001 - 5000 naira & 171 & 22.1 \\
above 5000 naira & 203 & 26.2 \\
Total & 773 & 99.7 \\
\hline
\end{tabular}

Note: Naira with the symbol $\mathbb{N}$ is the local currency in Nigeria $(\$ 1=$ $\$ 200$, but varies with prevailing exchange rate)

Also, direct liquid fuel consumption for the residential buildings is as shown in Table 3 . From the table, average liquid fuel consumption using the median as measure of central tendency indicates that 3 litres of kerosene was used per week (156 litres annually) while 15.5 litres of petrol was used per week (806 litres annually) by each household. Diesel use was negligible.

Table 3

Weekly Liquid Fuel Consumption of Households

\begin{tabular}{llll}
\hline Quantity & $\begin{array}{l}\text { Frequency } \\
\text { Kerosene }\end{array}$ & Petrol & Diesel \\
\hline None & 196 & 123 & 726 \\
$1-5$ litres & 320 & 70 & 3 \\
$6-10$ litres & 184 & 167 & 12 \\
11-20 litres & 62 & 178 & 7 \\
$21-30$ litre & 13 & 79 & 9 \\
$>$ 30litres & 0 & 158 & 18 \\
Total & 775 & 775 & 775 \\
\hline
\end{tabular}

For the consumption of LPG, the pattern is as shown in Table 4. From the table, the residents on the average refilled their $12.5 \mathrm{~kg}$ LPG cylinders every four weeks which is equivalent to $162.5 \mathrm{~kg}$ per household annually. Using equations 2 and 3, the primary energy content of grid electricity and direct fuel consumption was estimated. 
Citation: Ezema, I.C., Olotuah, A.O., and Fagbenle, O.I, S. (2016) Evaluation of Energy Use in Public Housing in Lagos, Nigeria: Prospects for Renewable Energy Sources. Int. Journal of Renewable Energy Development, 5(1),15-24, http://dx.doi.org/10.14710/ijred.5.1.15-24

$\mathrm{P}$ a g e $\mid 20$

Table 4

Frequency of LPG Cylinder Refill (12.5kg)

\begin{tabular}{lll}
\hline Category & Frequency & \% \\
\hline Not applicable & 285 & 36.8 \\
Weekly & 7 & 0.9 \\
Every two weeks & 41 & 5.3 \\
Every three weeks & 77 & 9.9 \\
Four weeks \& above & 365 & 47.1 \\
Total & 775 & 100.0 \\
\hline
\end{tabular}

Accordingly, grid electricity was estimated to be $12226 \mathrm{MJ}$ while LPG, petrol and kerosene were estimated to be $7686 \mathrm{MJ}, 26356 \mathrm{MJ}$ and $5497 \mathrm{MJ}$ respectively as depicted in Fig. 1. Hence, the annual operational energy for a residential unit was estimated at $51765 \mathrm{MJ}$ which gives an annual operational energy intensity of about $431.4 \mathrm{MJ} / \mathrm{m}^{2}$ and a life cycle operational energy intensity of $21570 \mathrm{MJ} / \mathrm{m}^{2}$ for a building life span of 50 years. It is evident from Fig. 1 that the relative contribution of grid electricity to total operational energy was less than a quarter while that of LPG, petrol and kerosene altogether constituted slightly above three quarters of total operational energy of a housing unit. Hence, direct fuel combustion accounted for the bulk of the operational energy profile of the buildings.

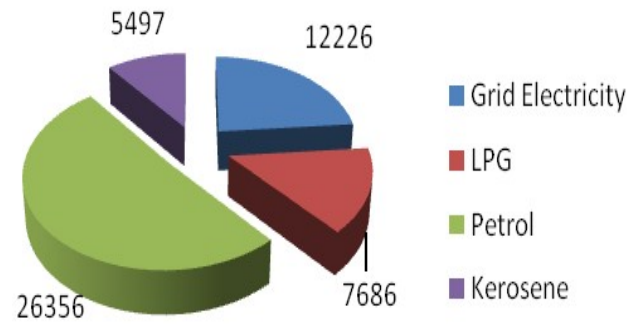

Figure 1 Annual Primary Energy Profile (MJ) per Housing Unit

\subsection{Renewable Energy Use}

Notwithstanding the advantages of renewable energy, the study showed that the use and diffusion of renewable energy technology such as solar and wind energy devices was very low (see Table 5). Specifically, $95 \%$ of the respondents do not use any form of renewable energy as they depend fully on grid electricity and use of electricity generating plants. It was also found that only $5 \%$ of the respondents use solar and wind energy. It appears from the result of the study that solar energy is used mostly for lighting as only 9 out of the 35 respondents that use solar energy reported using solar water heaters for domestic hot water supply (see Tables 5 and 6).
Table 5

Renewable Energy Use

\begin{tabular}{lll}
\hline Type & Frequency & \% \\
\hline None & 705 & 94.9 \\
Solar & 35 & 4.7 \\
Wind & 3 & 0.4 \\
Total & 743 & 100.0 \\
\hline
\end{tabular}

In addition, the result of the study further showed that the respondents also relied on grid electricity and direct fuel combustion for their domestic hot water needs. Accordingly, $48.4 \%$ of respondents use portable electric kettle for their domestic hot water needs and $48.1 \%$ of respondents boil water by using kerosene stoves. The portable electric kettles found in the study context are made to switch off power supply immediately the water boils. The high incidence of portable electric kettle is likely due to the fact that electric water heaters were not originally installed in the buildings. Respondents that reported use of electric water heater may have installed them in their houses. Table 6 clearly shows that even for domestic hot water needs, most of the respondents relied on nonrenewable energy sources. Only $1.2 \%$ of the respondents indicated use of solar water heaters.

Table 6

Sources of domestic hot water

\begin{tabular}{llll}
\hline Type & Categories & Frequency & Percentage \\
\hline Electric & Yes & 375 & 48.4 \\
Kettle & No & 400 & 51.6 \\
Electric & Yes & 107 & 13.8 \\
Heater & No & 668 & 86.2 \\
Solar Water & Yes & 9 & 1.2 \\
Heater & No & 766 & 98.8 \\
Kerosene & Yes & 373 & 48.1 \\
Stove & No & 402 & 51.9 \\
Gas Stove & Yes & 271 & 35.0 \\
& No & 507 & 65.0 \\
\hline
\end{tabular}

\subsection{Use of Energy Storage Devices}

In addition, the residents through responses to the questionnaire affirmed that energy storage in some form was practised.

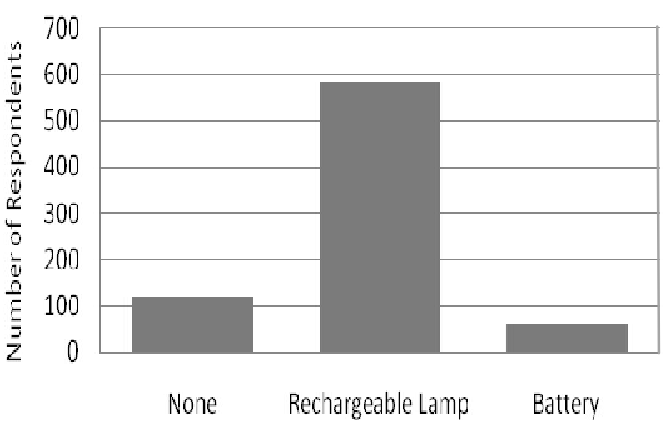

Figure 2 Use of Energy Storage Devices 
The result of the study as shown in Fig. 2 indicates that $76 \%$ of respondents (581) used rechargeable lamps for energy storage while $16 \%$ (120) do not use any form of energy storage appliance. Only 8\% (62) of the residents used grid-connected batteries for storing energy. Lead-acid batteries were used because they were the most prevalent and affordable type in the study area. Battery sizes were estimated in such a way that it can provide for the night time need for lighting, cooling with fans and for household electronics.

\subsection{Other Energy Sources}

As a result of the irregular supply of grid electricity to the residences, fossil fuel-powered private electricity generators were used in the residences mostly as backup for grid electricity. The result of this study as presented in Table 7 shows that with a total generator ownership of 812 units, the average ownership level of generators in the study area was 1.05 per household. The capacities of the generators ranged from below 1 KVA to above 5KVA and the detailed ownership profile is as shown in Table 7. The aggregated ownership profile is as depicted in Fig. 3. From the table and the figure, the lower capacity generators (3KVA and below) accounted for about $74.5 \%$ of the generators which is an indication of the respondents' preference for that class of generators. Further investigation through interview with the respondents indicated that the preference for the lower capacity generators was because it is the capacity that can support such basic end uses like lighting, cooling with fans, water pumping and to some extent refrigeration. Also the generators were powered by both petrol (PMS) and diesel (AGO) with the majority being powered by petrol. The above findings are in agreement with findings of an earlier study by Otegbulu (2011) which found that majority of the households used private electricity generators.

Table 7

\begin{tabular}{|c|c|c|c|c|c|}
\hline \multicolumn{2}{|l|}{$\begin{array}{l}\text { Type of } \\
\text { generator }\end{array}$} & $\begin{array}{l}\text { Generator } \\
\text { per } \\
\text { household }\end{array}$ & Frequency & $\begin{array}{l}\text { Number of } \\
\text { generators }\end{array}$ & $\begin{array}{l}\text { Total } \\
\text { generators }\end{array}$ \\
\hline \multirow{4}{*}{\multicolumn{2}{|c|}{$\leq 1 \mathrm{KVA}$}} & 0 & 601 & 0 & 191 \\
\hline & & 1 & 159 & 159 & \\
\hline & & 2 & 13 & 26 & \\
\hline & & 3 & 2 & 6 & \\
\hline $1.1 \mathrm{KVA}$ & - & 0 & 580 & 0 & 199 \\
\hline \multirow{2}{*}{ 2KVA } & & 1 & 191 & 191 & \\
\hline & & 2 & 4 & 8 & \\
\hline 2.1KVA & - & 0 & 563 & 0 & 227 \\
\hline \multirow[t]{2}{*}{ 3KVA } & & 1 & 197 & 197 & \\
\hline & & 2 & 15 & 30 & \\
\hline 3.1KVA & - & 0 & 654 & 0 & 126 \\
\hline \multirow{2}{*}{\multicolumn{2}{|c|}{$5 \mathrm{KVA}$}} & 1 & 116 & 116 & \\
\hline & & 2 & 5 & 10 & \\
\hline \multirow{3}{*}{$>5 \mathrm{KVA}$} & & 0 & 712 & 0 & 69 \\
\hline & & 1 & 57 & 57 & \\
\hline & & 2 & 6 & 12 & \\
\hline Total & & & & 812 & 812 \\
\hline
\end{tabular}

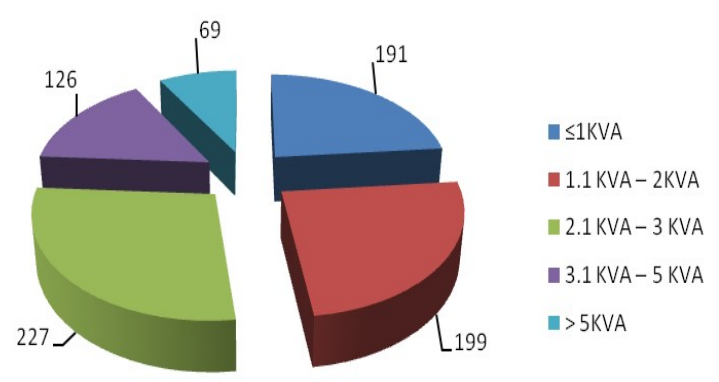

Figure 3 Aggregate Ownership/Types of Generators (Frequency)

The above explains the high incidence of direct fuel combustion, especially petrol, in the study area as indicated in Table 8 which further confirms that the predominant fuels used in the households were kerosene, petrol and LPG. Petrol was used by about $84 \%$ of the households and kerosene by about $75 \%$ of the households. Incidentally, the higher quality and more environmentally friendly LPG, was used by a lower proportion $(63 \%)$ of the households.

Table 8

Direct Fuel Use in the Households

\begin{tabular}{lllll}
\hline Type of Fuel & Users & & Non- users & \\
& & & & \\
& Frequency & $\%$ & Frequency & $\%$ \\
\hline Kerosene & 579 & 74.7 & 196 & 25.3 \\
Petrol & 652 & 84.1 & 123 & 15.9 \\
Diesel & 49 & 6.3 & 726 & 93.7 \\
LPG & 490 & 63.2 & 285 & 36.8 \\
\hline
\end{tabular}

Source: Extracted from Tables 3 and 4

\section{Discussions}

In the present study, operational energy sources were grid electricity, LPG, petrol and kerosene. In the Indonesian study (Surahman \& Kubota, 2012a, 2012b), operational energy sources were similar and included grid electricity, LPG and kerosene while the Indian study (Ramesh et al., 2013) was based on grid electricity supply only. Similarly, the Brazilian study (Paulsen \& Sposto, 2013) was based on grid electricity and LPG using national consumption statistics. The life cycle operational energy intensity of $21570 \mathrm{MJ} / \mathrm{m} 2$ estimated in present study is higher than the $17500 \mathrm{MJ} / \mathrm{m} 2$ in the Brazilian study but lower than the average value of $54910 \mathrm{MJ} / \mathrm{m} 2$ estimated in the Indian study (Ramesh et al., 2013). The differences can be attributed to a number of factors of which the energy mix is prominent. Brazil with high renewable energy content $(45 \%)$ as represented by hydroelectric plants has the most favourable energy mix of the three countries. The Indian energy mix is about $70 \%$ fossil fuel-driven while the Nigerian energy mix is lopsided in favour of fossil fuel powered thermal stations. The 
Citation: Ezema, I.C., Olotuah, A.O., and Fagbenle, O.I, S. (2016) Evaluation of Energy Use in Public Housing in Lagos, Nigeria: Prospects for Renewable Energy Sources. Int. Journal of Renewable Energy Development, 5(1),15-24, http://dx.doi.org/10.14710/ijred.5.1.15-24

$\mathrm{P}$ a g e $\mid 22$

operational energy intensity of $5350 \mathrm{MJ} / \mathrm{m} 2$ estimated for the luxurious apartment type in the Indonesian study is much lower than in the other studies which may be ascribed to the informal nature of the settlements studied and importantly due to the low space cooling requirement of the buildings which was estimated to be about 1 - $5 \%$ of life cycle operational energy. From the foregoing, the role of the energy mix in the operational energy intensity of buildings can be recognised.

A close observation of the grid electricity consumption profile of the study is also instructive. With an annual grid electricity consumption of $1200 \mathrm{kWh}$ per annum per household of five occupants, the annual per capita electricity use in the study area is about $240 \mathrm{kWh}$ which is higher than the country average of $149 \mathrm{kWh}$ and $156 \mathrm{kWh}$ per capita as estimated at different times by the World Bank (2013). However, in comparison with the annual per capita electricity consumption of $684 \mathrm{kWh}$ and $2438 \mathrm{kWh}$ for India and Brazil respectively, as indicated by the World Bank (2013), the energy poverty in Nigeria becomes apparent. However, the low grid electricity consumption in Nigeria is not reflected in the operational energy intensity as it is even higher than that of Brazil. This is indicative of an inefficient energy system and implies that other forms of energy in use in the study area may be contributing substantially to the energy mix and ultimately operational energy intensity.

The preferred energy for lighting and other appliances in the studied buildings is grid electricity. However, the findings underscore the low contribution of grid electricity to the primary energy consumption profile of the residential units investigated. This could be ascribed to the relatively low level of grid electricity supply to the residential buildings. Electricity generation in the study area has for some time been characterised by low investment and poor maintenance. As a result, electricity supply has not grown alongside growth in gross domestic product (GDP) and population as well as with improvement in the purchasing power of the population. A close look at the relative contribution of the different components of operational energy reveals that in the study area, grid electricity accounted for about $24 \%$ of total operational energy while it accounted for $66 \%$ of total operational energy in the Brazilian study and up to $68 \%$ in the Indonesian study. It is only in the present study that petrol combustion at household level contributed as high as $51 \%$ of the total operational energy. Hence the domestic energy scenario is tilted towards direct fuel combustion which is not only detrimental to health but also a negation of the drive towards decarbonisation of energy supply.

From the findings, domestic energy use especially for cooking was dominated by transition fuel such as kerosene. Even though LPG contributed more than kerosene to the operational energy profile of the buildings, more respondents used kerosene than LPG.
This is in agreement with national statistics (NBS, 2010) which indicates the prevalence of kerosene usage in the study area. Use of the more efficient LPG was not fully embraced by the households. Kerosene appears to be the most prevalent cooking fuel among low income residents while LPG was preferred by medium income residents. However, given the uncertainties in cooking fuel supply situation in the study area, residents tended to use both kerosene and LPG for cooking which is an indication that some form of energy stacking is applicable. Cooking energy as part of operational energy contributed $26 \%$ in the study area in comparison with $34 \%$ in the Brazilian study and $45 \%-79 \%$ in the Indonesian study.

From the foregoing, it can be inferred that energy supply to the studied buildings in inadequate. As established in previous studies, inadequate supply of delivered energy such as electricity is often an impetus to embrace renewable energy. Given the cost implications of grid electricity infrastructure in terms of generation and distribution, the use of off-grid or microgrid renewable energy becomes apposite. However, the results also indicate that use of renewable energy is as low as $5 \%$ in the study area but a marginal improvement on national statistics (NBS, 2010). The adoption of renewable energy technology to bridge energy supply gaps observed in studies such as Yuan et al, (2013; Sood et al, (2014; Luomi, 2014; Sangroya \& Nayak, 2015) was not observed in the present study. Renewable energy use has not been integrated to the national grid. In contrast, grid-connected renewable energy is gaining prominence in many other contexts. In addition, energy storage using system of batteries connected to mains supply is also poorly diffused

The concept of energy poverty could be said to characterise the study area given the fact that the vast energy resources are not optimally utilised. This is typically reflected in the grid electricity supply situation. With the challenges associated with generation and distribution, the electricity supply scenario is grossly inadequate and a clog in the wheel of economic development. It is also instructive that even in a scenario of low electrical energy supply, the residents' response to energy efficiency and conservation appear inappropriate. This is because instead of the low supply to facilitate efficient alternatives, it resulted in more inefficient strategies that increased the energy intensity profile of the studied buildings. Hence the recourse to captive power supply using private generators is a response to poor supply from the national grid. This largely supports the suppressed demand theory which refers to a scenario where energy services provided are inadequate due to poverty or lack of access to modern energy infrastructure (Afa \& Anerih, 2013). The energy scenario can improved with increased uptake of renewable energy technologies which can be facilitated by appropriate incentives. 


\section{Conclusion}

The study investigated operational energy use with particular reference to the use of renewable and nonrenewable energy sources in public residential buildings in Lagos, Nigeria. In all, non-renewable sources dominate renewable sources in operational energy use in the studied buildings. Operational energy intensity of the buildings was found to be comparable with what obtained in other studies in different contexts where per capita electricity consumption levels were higher. The relatively high operational energy intensity observed in the study area which is characterized by low electricity supply and consumption is indicative of inefficiency in the domestic energy scenario. Hence, a detailed study of the components of the operational energy indicated that direct fuel combustion to generate alternative to grid electricity, that is, captive generation accounted for about half of the operational energy intensity. The study also found that the opportunity provided by the low supply of electricity in the study area for RET use has not been effectively utilized.

Instead, carbon intensive fuel combustion for alternative electricity was deployed by majority of the residents. This resort to direct fossil fuel combustion in the residential units not only increased the operational energy intensity but also had the added disadvantage of increasing the carbon footprint of the residential units. In addition, direct fuel combustion at household levels can also pose safety challenges because of the highly volatile nature of the fuels. In fact, accidental explosions leading to loss of lives and property have been associated with direct fuel use in homes in the study area. In some instances entire families were wiped out due to overnight inhalation of carbon monoxide from portable electricity generators. Also, noise and chemical pollution with effects on occupants' health and wellbeing have been reported.

The policy implications of the above are manifold. Energy use and energy intensity regulations in building codes are needed for new buildings. Importantly, carbon emissions regulations for households as a complement to energy regulations are needed. In this respect, use of RET installations becomes necessary as a way of promoting low carbon energy in the study context. However, given the multiple tenancy structure associated with the studied residential units, installation of RET retrofits can be very challenging. Hence, policy should target how groups of housing units can be encouraged to install combined PV retrofits including micro-grid renewable installations.

The best opportunity for incorporating RETs in buildings in the study area lies with new buildings. In the study area of Lagos, the total housing deficit has been estimated to be about 5 million housing units. In order to mitigate the operational energy impact of 5 million additional housing units, the use of renewable energy should be considered and incorporated. The enormous advantage of renewable energy can be deployed during the procurement process leading to bridging the housing deficit. In this respect, the use of both PVs and building integrated PVs is recommended.

Further research on ways of encouraging renewable energy use in the study area is required. Given the high initial cost of RET as reported in previous studies, research should focus on long term economic benefits to the user as well as incentives to encourage uptake. Importantly, the use of incentives for the adoption of RET in new residential buildings as well as for the installation of RET as retrofits to existing buildings should be encouraged.

\section{References}

Afa, J. T.; \& Anerih, V. I. E. (2013). Proper energy mix: A solution to stable power supply in Nigeria, Academic Journal of Interdisciplinary Studies, 2(13), 93 - 101.

Ajayi, 0. 0. (2013). Sustainable energy development and environmental protection: Implications for selected states in West Africa, Renewable and Sustainable Energy Reviews, 26, 532 - 539.

Akinbami, J.; \& Lawal, A. (2010). Opportunities and challenges to electrical energy conservation and $\mathrm{CO} 2$ emissions reduction in Nigeria's building sector. Proceedings Cities and Climate Change Workshop, Midrand, South Africa, pp.345 - 365.

Akpan, U.; \& Isihak, S. (2013). Electricity access in Nigeria: Is off-grid electrification using solar photovoltaic panels economically viable?, Proceedings IEEE African Conference, Mauritius, 9 - 11 September.

Barth, B.; Mayer, J.; Trennpohl, N.; \& Bruckmann, R. (2015). Framework assessment for the photovoltaic business opportunities in Brazil 2014.

Elusakin, J.E.; Ajide, O. O.; \& Diji, J. C. (2014). Challenges of sustaining off-grid power generation in Nigerian rural communities, African Journal of Engineering Research, 2(2), 51 - 57.

Emodi, N. V.; \& Yusuf, S. D. (2014). Integrating renewable energy and smart grid technology into the Nigerian electricity grid system, Smart Grid and Renewable Energy, 5, 220 - 238.

Energy Commission of Nigeria (2003). National Energy Policy. Federal Republic of Nigeria, Abuja.

Energy Commission of Nigeria (2005). Renewable energy master plan, Final draft report, Energy Commission of Nigeria, Abuja.

Eronini, N. (2014). Tha adoption of photovoltaic systems among industries and residential houses in Southern Nigeria. Masters Thesis, Mid-Sweden University, Ostersund, Sweden.

Ezema, I. C. (2015). Profiling the environmental sustainability of residential buildings in Lagos, Nigeria using life cycle assessment, PhD Thesis, Covenant University, Ota, Nigeria.

Federal Government of Nigeria (2009). Report of the Vision 2020 National Technical Working Group, Abuja.

Federal Ministry of Power (2015), National Renewable Energy and Energy Efficiency Policy (NREEEP), Federal Republic of Nigeria.

Global Wind Energy Council (GWEC) (2014). Global Wind Statistics 2013.

Gorini, R. (2014). Brazilian energy efficiency market: using energy efficiency indicators: Strategy Proposal. www.cepal.org/drni/noticias/1/54071/Brazil.pdf. (Accessed 12/09/2015).

GREET (2010), The Greenhouse Gases, Regulated Emissions and Energy Use in Transportation Model, GREET1.8d.1. http://greet.es.anl.gov/ (accessed 08/01/2016).

Hofstrand, D. (2008), Energy Measurements and Conversions, File C686, University Extension, Iowa State University. www.extension.iastate.edu/agdm. (accessed 08/01/2016).

IINAS (2015), Development of the Primary Energy Factor of Electricity Generation in the EU-28 from 2010 - 2013, 
Citation: Ezema, I.C., Olotuah, A.O., and Fagbenle, O.I, S. (2016) Evaluation of Energy Use in Public Housing in Lagos, Nigeria: Prospects for Renewable Energy Sources. Int. Journal of Renewable Energy Development, 5(1),15-24, http://dx.doi.org/10.14710/ijred.5.1.15-24

$\mathrm{P}$ a g e $\mid 24$

International Institute for Sustainability Analysis and Strategy, Darmstadt, Germany.

Ilesanmi, A. 0. (2010). Urban sustainability in the context of Lagos mega city, Journal of Geography and Regional Planning, 3(10), 240 -252 .

Intergovernmental Panel on Climate Change IPCC (2007). Fourth assessment report: Climate change 2007. IPCC, Cambridge University Press, Cambridge UK

IRENA (2011), Renewable Energy Country Profiles Africa, International Renewable Energy Agency.

Jeje, B. (2013). Green buildings and low energy houses as adaptation tools for climate change in Lagos State, Paper $5^{\text {th }}$ Lagos State Climate Change Summit, Eko Hotel, Lagos, March 13 - 15.

KPMG (2013). A guide to the Nigerian power sector. KPMG Advisory Services, KPMG, Nigeria.

Lagos Bureau of Statistics (2013), Digest of Statistics 2013, Ministry of Economic Planning and Budget, Lagos State Government, Nigeria, Ikeja, Lagos.

Lagos State Government, LASG (2012a). Consultation Document for the development of a renewable energy policy, Ministry of Energy and Mineral Resources, Lagos State Government, Nigeria, Lagos

Lagos State Government LASG (2012b). Lagos State investor handbook: A guide to business and investment in Lagos State, Nigeria.

Luomi, M. (2014). Sustainable energy in Brazil: Reversing past achievements or realizing future potentials. OIES Paper SP34, The Oxford Institute for Energy Studies, Oxford, UK.

.Moula, M. M. E.; Maula, J.; Hamdy, M.; Fang, N.; \& Lahdelma, R. (2013). Researching social acceptability of renewable energy technologies in Finland. International Journal of Sustainable Built Environment, 2, $89-98$

Nasirov, S.; Silva, C.; \& Agostini, C. A. (2015). Investors' perspective on barriers to the deployment of renewable energy sources in Chile. Energies, 8, 3794 - 3914.

National Bureau of Statistics (2010). Annual abstracts of statistics 2010, Federal Republic of Nigeria.

Newborne, P.; and Welham, B. (2014). Joining the grid: Sustainable energy in Brazil. Development Progress Case Study Report, Overseas Development Institute, UK.

Obodeh, O.; \& Esabunor, T. (2011). Reliability assessment of WRPC gas turbine power station, Journal of Mechanical Engineering Research, 3(8), 286- 292.

Ogunleye, I. O.; \& Awogbemi, O. (2011). Constraints to the use of solar photovoltaic as a sustainable power source in Nigeria, American Journal of Scientific and Industrial Research, 2(1), 11 - 16.

Okedu, K. E.; Uhunmwangho, R.; \& Promise, W. (2015). Renewable energy use in Nigeria: The challenges and opportunities in mountainous and riverine regions, International Journal of Renewable Energy Research, 5(1), 222 - 229.

Otegbulu, A. C. (2011). Economics of green design and environmental sustainability, Journal of Sustainable Development, 4, 240 - 248.

Oyedepo, S. O.; Fagbenle, R. O.; Adefila, S. S.; \& Adavbiele, S. A. (2014). Performance evaluation and economic analysis of a gas turbine power plant in Nigeria, Energy Conservation and Management, 79, $431-440$.

Paulsen, J. S.; \& Sposto, R. M. (2013). A life cycle energy analysis of social housing in Brazil: Case study for the program "My house my life", Energy and Buildings, 57, 95 - 102.

Ramesh, T.; Prakash, R.; \& Shukla, K. K. (2013). Life cycle energy analysis of a multifamily residential house: A case in Indian context, Open Journal of Energy Efficiency, 2, 34 - 41.

Saidur, R.; Masjuki, H. H.; \& Jamaluddin, M. Y. (2007). An application of energy and exergy analysis in residential sector of Malaysia, Energy Policy, 35(2), 1053 - 1063.

Sambo, A. S. (2010). Renewable energy development in Nigeria, Paper at the World Future Council Strategy Workshop on Renewable Energy, Accra, Ghana, 21 - 24 June.

Sangroya, D.; \& Nayak, J. K. (2015). Development of wind energy in India, International Journal of Renewable Energy Research, 5(1), 1 $-13$.
Shaaban, M.; \& Petinrin, J. O. (2014). Renewable energy potentials in Nigeria: Meeting rural energy needs, Renewable and Sustainable Energy Reviews, 29, 72 - 84.

Sood, R.; Aggarwal, R. K.; Mahajan, P. K.; Bhardwaj, S. K.; \& Sharma, S. (2014). Estimation of domestic energy consumption and carbon dioxide emission in Mid Himalayan region of Himachal Pradesh, India, Journal of Agriculture and Environmental Sciences, 3(1), 141 $-147$.

Spors, F. (2011). Suppressed demand: Definition and consideration of different approaches to address it in CDM methodologies, UNFCCC Standardisation Workshop, Carbon Finance Unit, World Bank, June.

Sriwannawit, P.; \& Laestadius, S. (2013). Diffusion of photovoltaic systems for rural electrification in Thailand, International Journal of Energy and Environment, 4(1), 49 - 58.

Surahman, U.; \& Kubota, T. (2012a). Development of a simplified LCA model for residential buildings in Indonesia - A pilot survey in Bandung, AIJ Journal of Technical Design, 18(40), 1003 - 1008.

Surahman, U.; \& Kubota, T. (2012b). Life cycle energy and CO2 emissions in unplanned residential buildings of Indonesia: A case study in Bandung, Proceedings 28 ${ }^{\text {th }}$ PLEA Conference, Lima, Peru, 7 -9 November.

Taylor, P.; Lavange d' Ortigue, O.; Trudeau, N.; \& Francoeur, M. (2008). Energy efficiency indicators for public electricity production from fossil fuel, IEA Information Paper, International Energy Agency.

UN Habitat (2008). State of the World's Cities 2008/2009. London, Earthscan.

United Nations Development Programme UNDP (2010). Promoting energy efficiency in residential and public sector in Nigeria, Nigeria-EE Appliances Project Document, UNDP.

United Nations Environment Programme UNEP (2007). Buildings and Climate Change: Status, challenges and opportunities. UNEP.

US Department of Energy: Energy Efficiency and Renewable Energy (2008). Energy efficiency trends in residential and commercial buildings, US Department of Energy, Washington DC.

USEIA (2015), Country Analysis Brief: Nigeria, US Energy Information Administration.

Vossenaar, R.; \& Jha, V. (2010). Deploying energy efficiency and renewable energy technologies in residential and commercial buildings: What are trading opportunities for developing countries. Global Platform on Climate Change Trade and Sustainable Energy, Issue Paper No. 11, Internation Centre for Sustainable Development.

World Bank (2013), Electric power Consumption (kWh per capita). The World Bank, Washington DC.

World Bank, (2014), Access to electricity (\% of population). The World Bank Group, Washington DC.

World Resources Institute (2012). Green house gases calculation tools for stationary emission sources, World Resources Institute, Washington DC.

Yuan, X.; Wang, X. \& Zuo, J. (2013). Renewable energy in buildings in China: A review, Renewable and Sustainable Energy Reviews, 241 $-8$. 